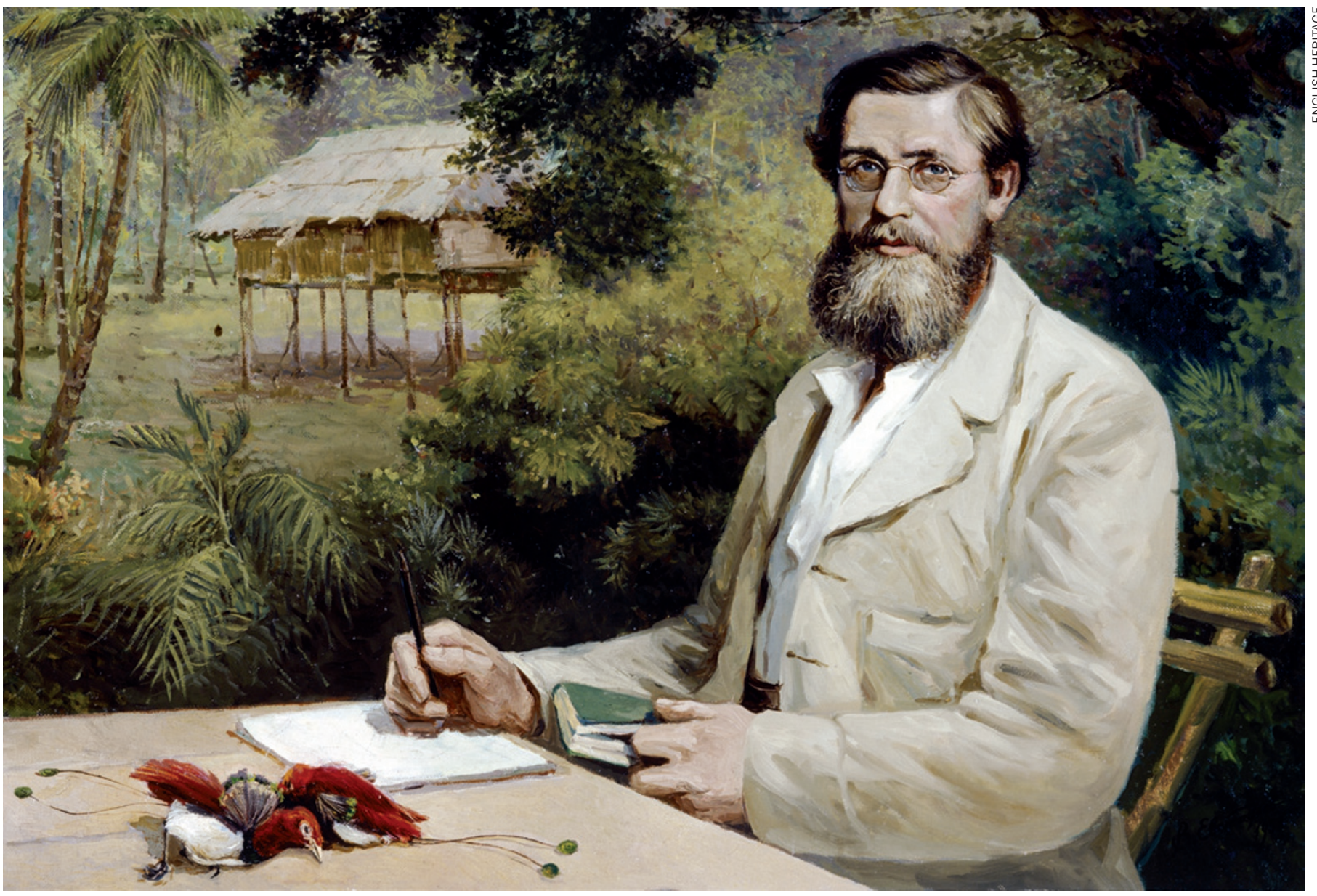

\title{
Evolution's red-hot radical
}

\section{Sidekick status does Alfred Russel Wallace an injustice. He was a visionary scientist in his own right, a daring explorer and a passionate socialist, argues Andrew Berry.}

$\mathrm{A}$ lfred Russel Wallace is too often remembered as little more than Charles Darwin's goad. Darwin's procrastination in publishing his ideas on evolution by natural selection was ended by the arrival from Indonesia of a manuscript from Wallace that outlined the very same idea. Papers by both men were read at the Linnean Society on 1 July 1858 (ref. 1). On the Origin of Species, published by Darwin the following year, brought the theory into the public eye.

Wallace's finest moment has condemned him to be forever Watson to Darwin's Holmes. Characteristically, Wallace actively promoted this perception. He entitled his major 1889 book on evolution Darwinism and, at the 1908 event to mark the 50th anniversary of the joint reading, played down his contribution: "I was then (as often since) the "young man in a hurry": he [Darwin] the painstaking and patient student, seeking ever the full demonstration of the truth that he had discovered, rather than to achieve immediate personal fame."

Sidekick status does Wallace an injustice. He was a visionary scientist in his own right, a daring explorer and a passionate socialist. This year's conferences and exhibitions marking a century since his death in 1913 (see go.nature.com/icpkp8) provide an excellent opportunity to reappraise his huge scientific legacy, which ranged from discovering natural selection to defining the term species, and from founding the field of evolutionary biogeography to pioneering the study of comparative natural history.

\section{AMAZON APPRENTICESHIP}

Born in 1823 into genteel poverty, Wallace left school at 13 years old to assist his brother, a land surveyor. Tramping the English countryside introduced Wallace to his first scientific interest: plants. He became a serious student of natural history in 1844 , when another young, self-educated naturalist, Henry Walter Bates (of future Batesian mimicry fame), introduced him to beetle collecting. In 1847, dissatisfied with "a mere local collection", Wallace wrote to Bates, "I should like to take some one family, to study thoroughly - principally with a view to the theory of the origin of species."

So, with extraordinary daring, the two neophytes headed to the Brazilian Amazon in 1848. Wallace stayed for 4 years, Bates 11. They funded their scientific expedition by selling specimens.

Wallace headed home in 1852. Because of a customs issue, he found many of the specimens he had been sending to London held up in Manaus in Brazil, at the confluence of the Amazon and Rio Negro. Reunited with the fruits of years of perilous labour and accompanied by a small menagerie of living animals he had ferried across the continent 
to Belém at the mouth of the Amazon, Wallace must have fantasized about the impact of his arrival on London society: imagine walking into Victorian scientific salon with a toucan on your arm.

It was not to be. In the middle of the Atlantic, Wallace's ship caught fire and went up like a tinderbox. He had time to grab only a small box of drawings before being a part of what is surely one of the most poignant scenes in the history of science. Hopeful that the burning wreck would attract other shipping, Wallace and the crew stayed close. He watched as the living animals he had brought such a distance - his pets and his passport to the scientific big time in London - perished on the stricken vessel. "Many of the parrots, monkeys, and other animals we had on board, were already burnt or suffocated; but several had retreated to the bowsprit out of reach of the flames... quite unconscious of the fate that awaited them."

Wallace spent ten days adrift in an open boat before being rescued. His Victorian stiff upper lip never quivered: "During the night I saw several meteors, and in fact could not be in a better position for observing them, than lying on my back in a small boat in the middle of the Atlantic."

Having lost almost everything but determined to make his name as a naturalistscientist, Wallace took to sea once more in 1854 , en route to Singapore, from where launched his second set of extraordinary explorations. The Amazon was his scientific apprenticeship; his eight-year journey through southeast Asia was, Wallace wrote, "the central and controlling incident of my life".

Wallace ranged from peninsula Malaysia to Western New Guinea (see page 165). This time, despite his many dangerous adventures in small boats in remote archipelagoes, Wallace's extensive collections made it safely back to England, complete with some 1,000 species new to science. By his return in 1862, he was a member of the scientific elite. He had impressed hungry collectors and institutions such as the British Museum with his constant stream of specimens. And, thanks to the Linnean Society reading and a stream of innovative papers from the field, he had made a name for himself as biological theorizer.

\section{SCIENTIFIC DEBUT}

In forcing him to undertake a second expedition, Wallace's mid-Atlantic catastrophe inadvertently completed his biogeographical education. As a collector, he was interested in the distribution of animals: he needed information on where he could find particular species, and he was sensitive to geographical transitions from one species to another. In one of his early Amazon papers, he complains about the lack of precision of previous naturalists in designating the ranges of monkey species.

Wallace had a prodigious ability to spot patterns in the apparently chaotic (and largely uncatalogued) world of tropical diversity. This is the skill of the true naturalist: to generate a mental database of observed plants and animals that can be referenced when similar forms are encountered elsewhere. It led to his first attempt at biological generalization, a paper he wrote in 1855 while in Sarawak, Borneo: 'On the Law which has Regulated the Introduction of New Species' (often called the Sarawak Law) ${ }^{2}$.

It was a stunning scientific debut. He italicized the paper's take-home message, "Every

"The origin of species was, Wallace recognized, a genealogical process." species has come into existence coincident both in space and time with a pre-existing closely allied species". In other words, related species tend to be found in the same geographical area (all kangaroos are in Australasia, for instance) and, as fossils, in contiguous strata (all ceratopsid dinosaurs appear in the late Cretaceous). The origin of species was, Wallace recognized, a genealogical process.

A remarkable feature of the Sarawak law is Wallace's synthetic use of published information. In Borneo, Wallace had little or no access to fossil material: wet tropical environments are famously fossil-poor because vegetation and soil conceal underlying rock formations. In the absence of academic libraries, he relied on his phenomenal memory and whatever published accounts of the fossil record he could carry. Charles Lyell's Principles of Geology (1830-33) was his bible. Whereas Darwin's appreciation of the fossil record was acquired in the field in South America, Wallace's palaeontological insights were book-learnt. This makes his magisterial two-volume overview of the global distribution of life - The Geographical Distribution of Animals (1876) - all the more extraordinary in its synthesis of living and fossil data.

Wallace's pattern-spotting led him to another concept fundamental to evolution. In his brilliant 1865 paper on the papilionid butterflies of southeast $\mathrm{Asia}^{3}$, he parses variations within and among populations, among subspecies and species, and arrives at this definition: "Species are merely those strongly marked races or local forms which, when in contact, do not intermix, and when inhabiting distinct areas are generally believed to have had a separate origin, and to be incapable of producing a fertile hybrid offspring."

It is emblematic of history's neglect of Wallace that most undergraduates today are taught that the biological species concept was introduced in 1942 by Ernst Mayr ${ }^{4}$.

Becoming familiar with the wet tropics of both the New and Old Worlds put Wallace in a position to ask questions on a larger scale. Given climatic similarities, why do two regions have markedly different fauna? Wallace had laid the groundwork for this field - historical biogeography — in his 1857 paper about the Aru Islands off western New Guinea ${ }^{5}$, and eventually made it his own. He wrote "how totally the productions of New Guinea differ from those of the Western Islands of the Archipelago, say Borneo", despite the likeness of their "climate and physical features". He also pointed out that, despite the contrast between the physical conditions of Australia and New Guinea, "the faunas of the two, though mostly distinct in species, are strikingly similar in character." Had Borneo and New Guinea been geologically connected, Wallace hinted, their faunas would have been similar.

The Sarawak law built on this, in noting that the distributions of species are dictated partly by environmental considerations (some trees, for example, are tropical specialists) but mostly by the quirks of history. It is this line of thinking that culminated in The Geographical Distribution of Animals. If only Wallace had lived to see the unveiling of the theory of continental drift in the 1960s that clinched it: Australia and New Guinea are on one tectonic plate, Borneo on another.

\section{LUCKY BREAK}

It is tempting to see echoes between Wallace's serendipitous path through life and his contingent interpretation of natural systems: his most famous biogeographical discovery also had a dose of luck. In 1856, having missed a connection as he tried to make his way to Sulawesi, he spent a couple of months on the islands of Bali and Lombok, and noted drastic differences in the wildlife even though the islands are only some 35 kilometres apart. To the south and east, the Australian fauna dominated; to the north and west, the Asian one. He had identified an ancient biogeographic split across southeast Asia that biologist Thomas Henry Huxley later dubbed 'Wallace's Line'.

Wallace's 1858 discovery of natural selection pulled these strands together. While in a fever on the Maluku islands (Moluccas), he was pondering another biogeographic discontinuity: that between the Austronesian people of southeast Asia and the Melanesians of New Guinea. Drawing, like Darwin, on the work of economist Thomas Malthus, he focused on competition for limited resources. Combining this with his appreciation of variation within species that came from being a collector, natural selection was, for him, a logical step.

Wallace was disappointed that his heretical Sarawak law paper had barely made a ripple. His agent in London complained that "theorizing" was not useful and that Wallace 


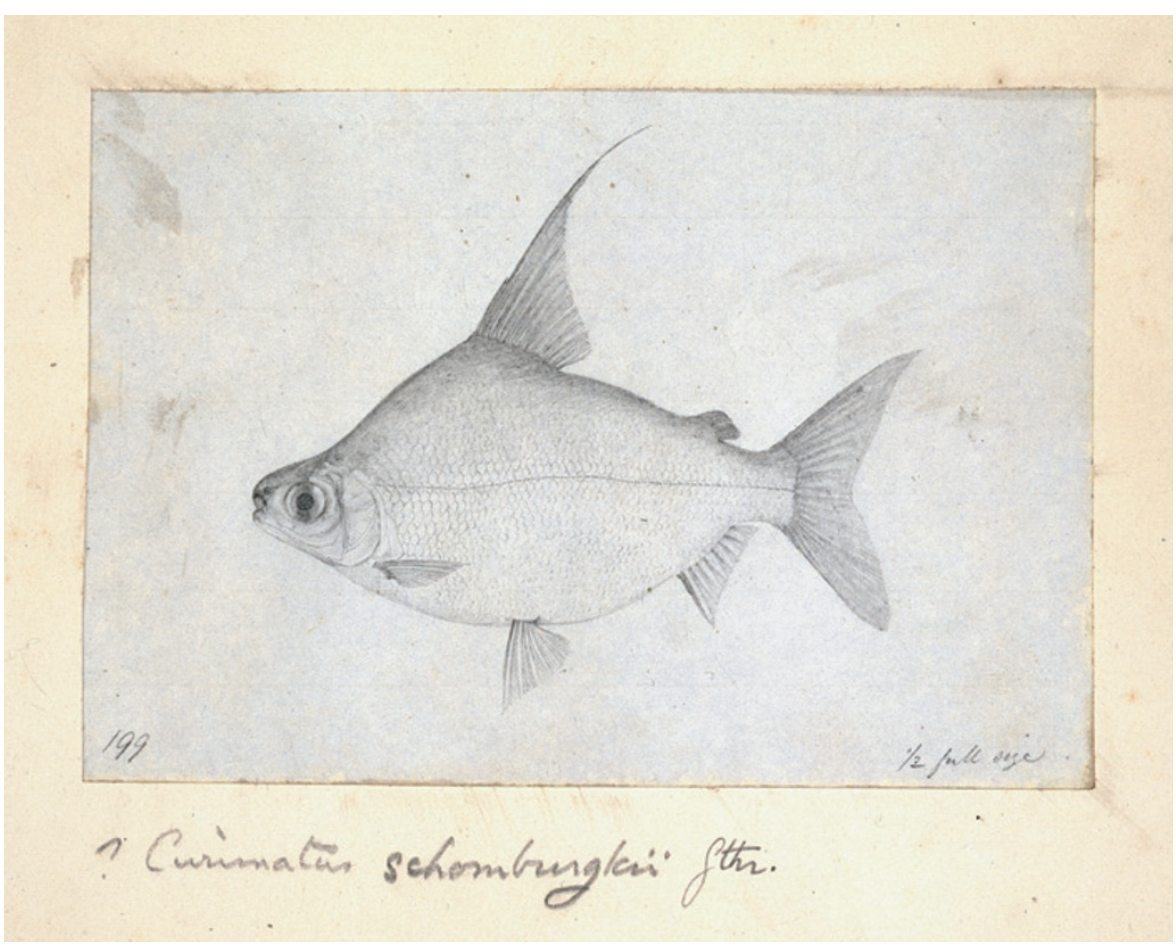

One of the few Amazon drawings rescued by Alfred Russel Wallace from his burning ship in 1852.

should "collect more facts". To save his natural-selection paper from the same fate, Wallace sent the manuscript to a senior colleague in the hope that his endorsement would give it prominence. That colleague was Darwin. How different things may have turned out had Wallace instead sent the manuscript directly to a journal.

\section{BEYOND EVOLUTION}

Standard histories of Wallace sometimes refer to the "other Wallace", giving the impression of a flake who used his newfound scientific celebrity to plunge into dubious causes, from suffrage and socialism to spiritualism and phrenology. But Wallace's world view was far more coherent ${ }^{6}$ than is often claimed. Take, for example, his perspective on human evolution.

Of the several disagreements between Wallace and Darwin, the most significant was on human evolution: Wallace came to believe that natural selection alone could not account for our species. Darwin was horrified, writing to his friend in 1869: "I hope you have not murdered too completely your own and my child." Two factors are behind Wallace's defection on this issue.

First, he had become a convinced spiritualist. Seances by fraudulent mediums keen to fleece fashionable Victorians were especially popular among free-thinkers such as Wallace. They had disavowed established religion but hankered for something to fill the void. Wallace even attempted to convince his scientific colleagues that spiritual forces were undetectable by scientific means because the technology had not yet been devised. In the days before microscopes, he wrote, who would have believed that a drop of water from the Thames was swarming with tiny creatures? As a spiritualist, he had to assert the existence of some kind of non-material intervention in the genesis of humans.

His other reason for rejecting natural selection as sufficient for human evolution is more scientific. Having spent some 12 years living among and being dependent on people deemed by Victorians to be savages, Wallace, unlike even the most liberal abolitionists, was no racist. "The more I see of uncivilized people, the better I think of human nature on the whole, and the essential differences between so-called civilized and savage man seem to disappear."

For Wallace, this enlightened social perspective posed an evolutionary problem. He appreciated that an Aru islander living in a mud hut has the same mental attributes as a member of London's scholarly Athenaeum club. Given the necessary training, he felt, the islander would be able to play Chopin and to declaim Ovid; yet this potential would never be realized on the Aru Islands. Thus, many humans have abilities that they never have the opportunity to use.

Such a situation, Wallace reasoned, cannot evolve through natural selection alone, which promotes only those traits that are useful. Wallace concluded that human evolution required some divine intervention. This argument shows an excellent appreciation of the mechanics of natural selection, even if we are now comfortable with the idea of the brain having evolved under natural selection for specific adaptive purposes, with many of its attributes - including Chopinplaying and Ovid-declaiming - being simply by-products of the resulting organ.

Whatever one's qualms about some of Wallace's non-scientific causes, one cannot fail to be impressed by the passion and intensity he brought to them. He was in many ways the prototype of a socially engaged scientist. A constant theme of his 20 books and almost 800 articles is sympathy for the underdog: whether that be the poor ("To allow one child to be born a millionaire and another a pauper is a crime"); disenfranchised women ("women are human beings; therefore they should have votes as well as men."); or the threatened redwoods of California ("Let us hope that ... care will be taken, before it is too late, to preserve... some more extensive tracts of forest.").

Meanwhile, Wallace remained engaged and productive as a scientist throughout his life. One of his last books, Is Mars Habitable? (Macmillan, 1907), arguably established the field of astrobiology (see U. Kutschera Nature 489, 208; 2012). He wrote extensively on the evolution of animal colouration, especially crypsis (camouflage), aposematism (warning colouration) and mimicry. And he suggested that natural selection may actually facilitate speciation by promoting the evolution of inviability or infertility of hybrids between incipient species (sometimes called the Wallace $\mathrm{effect}^{7}$ ). The most significant of Wallace's contributions, however, were his synthetic works on evolutionary biogeography: The Geographical Distribution of Animals and Island Life (1880), which established the field and set the bar high for future contributions.

As we remember Wallace 100 years after his death, let us celebrate his remarkable scientific achievements and his willingness to take risks and to advocate passionately for what he believed in. He was, after all, both a scientist, and, in his own assessment, a "Red-hot Radical, Land Nationaliser, Socialist, Anti-Militarist, etc., etc., etc.” In short, a whole lot more than Darwin's goad.

Andrew Berry is lecturer in Organismic and Evolutionary Biology at Harvard University, Cambridge, Massachusetts, USA. e-mail:berry@oeb.harvard.edu

1. Berry, A. \& Browne, J. Nature 453, 1188-1190 (2008).

2. Wallace, A. R. Annals and Magazine of Natural History 16, 184-196 (1855)

3. Wallace, A. R. Transactions of the Linnean Society of London 25, 1-71 (1865).

4. Mayr, E. Systematics and the Origin of Species (Columbia Univ. Press, 1942).

5. Wallace, A. R. Annals and Magazine of Natural History 20, (Suppl.) 473-485 (1857).

6. Fichman, M. An Elusive Victorian: The Evolution of Alfred Russel Wallace (Univ. Chicago Press, 2004).

7. Johnson, N. A. in Natural Selection and Beyond: The Intellectual Legacy of Alfred Russel Wallace (eds Smith, C. H. \& Beccaloni, G.) 114-124 (Oxford Univ. Press, 2008). 